\title{
Maintenance of Certification Questions and Answers
}

Recently, we introduced improvements to the American Board of Family Medicine's Maintenance of Certification Program for Family Physicians (MC-FP). The most important new enhancement is the opportunity for Diplomates to extend their certification period from 7 to 10 years by regularly completing $\mathrm{MC}-\mathrm{FP}$ requirements in a timely fashion. This major improvement in MC-FP will help Diplomates keep up with rapid advances in medicine, while duly recognizing the achievement of full and timely participation in MC-FP. This graph and FAQs are intended to illustrate the requirements of the 7-year vs. the new 10 -year certificate.

\section{Q Can anyone extend their certificate by 3 years?}

A Any Diplomate who has started MC-FP — that is any Diplomate who has certified or recertified since 2003-may opt to extend their certification. Those Diplomates who have not yet entered MC-FP will do so after they next recertify. At that time, they may also choose the option to extend the certificate that they receive at that time. Anyone choosing to extend their certificate will have to successfully complete a combination of modules and meet the required deadlines for this process. The process has been sectioned into 3-year stages with specific requirements that must be successfully completed by the end of each 3 -year stage. The requirements for each stage are the completion of two Part II modules (currently the only available Part II modules are the Self-Assessment Modules) and one Part IV module (currently the only available Part IV modules are the Performance in Practice Modules and the METRIC modules produced by the American Academy of Family Physicians).

\section{Q What comprises a Self-Assessment Module $(S A M)$ ?}

A A SAM is composed of the 60 -question Knowledge Assessment followed by a Clinical Simulation. The SAMs are the modules that are required to successfully complete Part II of MC-FP. There will be 6 different health topics to choose from in 2006, with more added every year.

\section{Q What comprises a Performance in Practice Module (PPM)?}

A A PPM is composed of a Quality Improvement activity that takes course over a 3-month to 6-month period. The PPMs are the modules that are required to successfully complete Part IV of MC-FP. There will be 4 different health topics to choose from in 2006, with more added every year.

\section{Q Are there any other module options?}

A We have established a process by which outside providers can submit Part II or Part IV modules to us for approval. Currently, only one such Part IV module has been approved and that is the METRIC module as provided by the American Academy of Family Physicians.

\section{Q How do I know which modules I need to take?}

A If you are currently in MC-FP and have chosen the option that will extend your current certificate by 3 years (essentially creating a 10 -year certificate period from when you last recertified), the requirements are two Part II modules and one Part IV module for a total of 3 modules for each 3-year Stage. You may complete these modules at your own pace, doing all in one year or one every year, but they all must be completed by the end of each 3-year Stage. A total of 3 Stages, or 9 modules, must be completed during the 10-year MC-FP cycle.

If you do not wish to choose the three-year extension option, you will stay in the current 7 -year MC-FP cycle and will need to complete 6 Part II modules and one Part IV module. If you do choose the 3-year extension option and fail to complete the requirements noted above for any Stage, you will fall back into the original 7-year MC-FP cycle. 


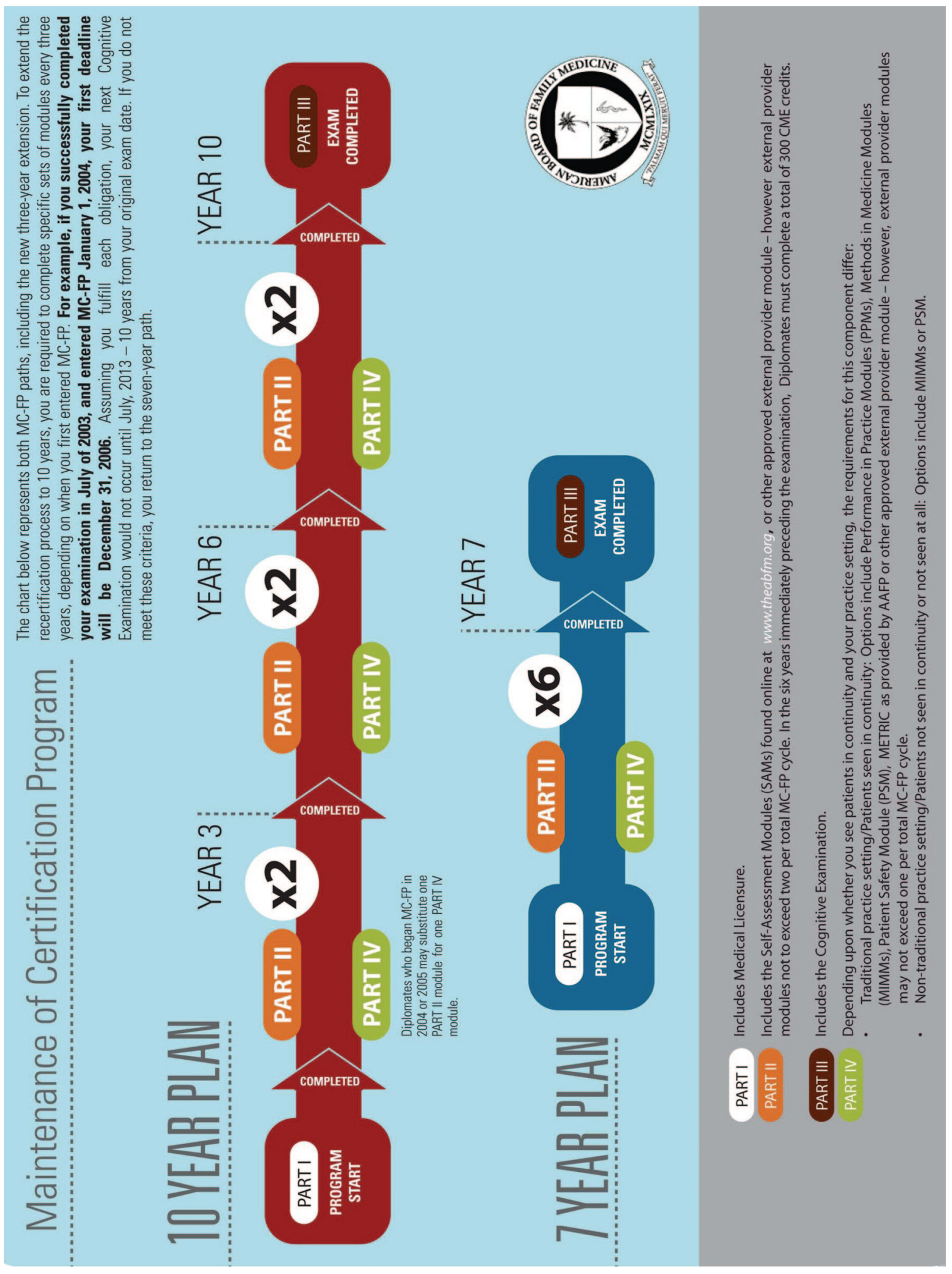

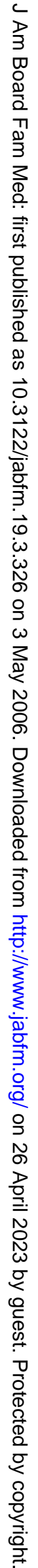

If you are currently participating in the MC-FP program, you may log on to your Physician Portfolio and check the Track Your Progress page. This area keeps you informed as to what modules you have successfully completed and what you still need to complete to fulfill the requirements for each stage of MC-FP. For example, you may have completed two SAMs and now need to complete one 
PPM, which will be indicated in the Track Your Progress panels. Remember that until the new MC-FP options are fully implemented in January 2007, your progress in your Physician Portfolio will be based on the current 7-year MC-FP cycle.

\section{Q I am not a practicing physician; do I still need to participate?}

A Yes, physicians who are administrators or who practice in settings that do not allow them to complete a PPM or METRIC module (eg, urgent care or locum tenens) will still be required to participate in MC-FP. These Diplomates will elect to complete a different type of Part IV activity. These options include a Methods in Medicine Module (MIMM) or the Patient Safety Module (PSM). The first MIMM will be on information management and will be available in 2007. The PSM will come on line in 2008. The American Board of Family Medicine will be adding more MIMM options in the future that will accommodate these Diplomates.

\section{Q Are the requirements the same for everyone?}

A In summary, the requirements are the same; however, your pathway to obtaining a 3-year extension will vary somewhat, in terms of the combination of different types of modules, depending on whether or not you see patients in a clinical setting that will allow you to complete a PPM.

\section{Q I obtained my 7-year certificate in 2003; bow do I extend my certificate to 2013 instead of 2010?}

A You must hurry and complete all the requirements of the first 3-year stage by the end of 2006 to remain eligible for the 3 -year certificate extension. As an inaugural MC-FP participant, you may choose to complete either 3 SAMs or 2 SAMs and one PPM for your first 3-year stage to attain initial eligibility for certificate extension. This would be followed by two Part II modules and a Part IV module by 2009, and two more Part II modules and a Part IV module by 2013. You would then sit for your next examination in 2013.
I obtained my 7-year certificate in 2004; bow do I extend my certificate to 2014 instead of 2011?

A You must complete all the requirements of the first 3-year stage by the end of 2007 to remain eligible for the 3-year certificate extension. You may choose to complete either 3 SAMs or 2 SAMs and one PPM for your first 3-year stage to attain initial eligibility for certificate extension. This would be followed by 2 Part II modules and a Part IV module by 2010, and 2 more Part II modules and a Part IV module by 2014. You would then sit for your next examination in 2014.

\section{Q I will be recertifying in 2007, 2008, or 2009; can I extend my current certification period for 3 more years?}

A Not until you take your next recertification examination. Only Diplomates who have started MC-FP, that is any Diplomate who has certified or recertified since 2003, may opt to extend their certification. Those Diplomates who have not yet entered MC-FP will do so after they next recertify. To clarify who is currently participating in MCFP, approximately half of all Diplomates have started MC-FP at this point (those Diplomates who certified or recertified in 2003, 2004, and 2005). The other half will start participating in MC-FP soon (those Diplomates who will certify or recertify in 2006, 2007, 2008, and 2009), and may choose to extend their next certification period.

\section{Q If I just want to retain or qualify for a 7-year certificate, does that mean I can dispense with taking any modules?}

A No. Participation in MC-FP is still a requirement for eligibility to sit for the recertification examination. That is not an element of the program that has changed. You will still need to complete 6 Part II modules (currently the SAMs) and one Part IV module (currently the PPMs or METRIC) before your next examination.

More detailed information on the improvements to the MC-FP and FAQs are available on our website wwww.theabfm.org > by clicking on MC-FP Program Enhancements. 